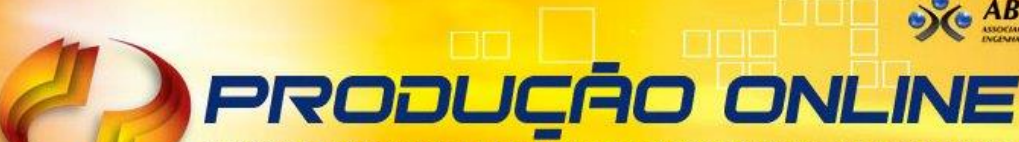 \\ REVISTA CIENTIFICA ELETRÓNICA DE ENGENHARIA DE PRODUÇÃO \\ ISSN 1676-1901
}

\section{CONFIGURAÇÃO DO ELO DE FORNECIMENTO DA CADEIA DE SUPRIMENTOS SUCROALCOOLEIRA NA REGIÃO DA MATA NORTE DE PERNAMBUCO}

\section{CONFIGURATION OF THE SUPPLY LINK OF THE SUGAR AND ALCOHOL SUPPLY CHAIN IN THE REGION OF MATA NORTE DE PERNAMBUCO}

\author{
Bheattryz Rayssa Silva Soares* E-mail: bheattryz-rayssa@hotmail.com \\ Maria Luciana De Almeida* E-mail: lucianalmeida.pe@gmail.com \\ *Universidade de Pernambuco (UPE), Recife, PE
}

Resumo: A cadeia sucroalcooleira tem significativa importância na região nordeste e vem passando por um processo de reestruturação nos últimos anos. O elo de fornecimento se mostra como aquele que tende a apresentar maiores desafios. Neste sentido, este estudo teve como objetivo compreender como se configura o fornecimento de cana de açúcar na região da Mata Norte de Pernambuco. A base metodológica foi à pesquisa qualitativa e os instrumentos de coleta de dados utilizados foram observação e entrevista. Os principais resultados relacionam as condições do setor sucroalcooleiro na Mata Norte; a percepção dos fornecedores sobre o governo e associações sindicais e o desempenho da cooperativa na gestão de uma usina; e as visões do pequeno e grande produtor. Foi evidenciado que $o$ elo de fornecimento de cana-de-açúcar passa por grandes dificuldades, pois os pequenos produtores têm dificuldades em manter a produção que gera custos altos que eles não conseguem subsidiar. Além disso, o poder exercido pelas usinas pode afetar o setor, visto que os fornecedores, por falta de opções, precisam se moldar a cadeia, contudo, as próprias usinas vêm tendo dificuldades em se manter em funcionamento.

Palavras-Chave: Cadeia de suprimentos. Fornecedores. Setor sucroalcooleiro.

\begin{abstract}
The sugar and alcohol chain has significant importance in the Northeast region and has been undergoing a restructuring process in recent years. The supply link is shown to be one that tends to present greater challenges. In this sense, this study aimed to understand how the supply of sugar cane is configured in the region of Mata Norte in Pernambuco. The methodological basis was qualitative research and the data collection instruments used were observation and interview. The main results relate to the conditions of the sugar and alcohol sector in Mata Norte; the suppliers' perception of the government and union associations and the cooperative's performance in managing a plant; and the visions of small and large producers. It was evidenced that the sugar cane supply link is going through great difficulties, since small producers have difficulties in maintaining production that generates high costs that they are unable to subsidize. In addition, the power exercised by the mills can affect the sector, since suppliers, due to a lack of options, need to shape the chain, however, the mills themselves are having difficulties keeping them up and running.
\end{abstract}

Keywords: Supply chain. Suppliers. Sugar and alcohol sector.

\section{INTRODUÇÃO}

A cadeia de suprimentos surgiu como uma evolução do conceito de logística. Para Vasconcelos (2015, p. 23) a cadeia de suprimentos é o gerenciamento do "fluxo de informações e produtos, tanto na empresa fabricante quanto entre seus parceiros 
ao longo da cadeia produtiva". A ideia é desenvolver um gerenciamento integrado visando à obtenção de maior valor agregado bem como diminuição dos custos decorrentes de desperdícios e retrabalhos, ou seja, elevando o nível de serviços ofertado. A cadeia de suprimentos envolve a logística que se divide em quatro aspectos: suprimentos, processamento interno, distribuição e retorno de bens pósvenda ou pós-consumo (VASCONCELOS, 2015). Uma das cadeias significativamente importantes no nordeste é a sucroalcooleira, ou seja, de derivados da cana de açúcar.

A história do Nordeste é marcada pela cana de açúcar. Dias (2017) afirma que o setor sucroalcooleiro, ainda hoje, é uma das principais atividades industriais desenvolvidas no Nordeste. Mesmo que o cenário produtivo seja diferente do passado esta indústria continua sendo importante para a economia nordestina. Segundo informações da Federação das Indústrias do Estado de São Paulo - FIESP (2017), nos últimos meses daquele ano, o setor tinha retomado o seu crescimento, sendo processo de recuperação do setor moroso e gradativo. O setor sempre teve dificuldades de si manter em funcionamento, muitas usinas acabaram passando por dificuldades, ao longo do tempo, o que acarretou em mudanças de gestão e, em muitos casos, no encerramento das atividades. A revitalização do setor veio com a entrada de cooperativas, o que possibilitou a reabertura de algumas usinas, trazendo crescimento para o setor, mesmo que as dificuldades ainda existam.

Neste trabalho o foco será direcionado para o elo de suprimentos, a qual congrega todos os processos envoltos entre fornecedores e organizações compradoras. Essa ênfase se justifica pelo fato de que as dificuldades encontradas pelas usinas são repassadas para seus fornecedores, os quais acabam se deparando com dificuldades de obter sustentabilidade econômica na comercialização da cana. Neste contexto, dentro desta cadeia um dos elos mais complexos e no qual se enfrentam mais dificuldades é o de suprimentos, o qual é composto pelos fornecedores de cana de açúcar. Isso acontece porque, em geral, eles são pequenos produtores de regiões pobres do estado, que mesmo tendo uma grande importância para a cadeia produtiva, enfrentam à falta de apoio e incentivo pelo governo como também os altos custos para produzir a cana de açúcar.

Com base nestas alusões surge o seguinte questionamento: como se configura o elo de fornecimento da cadeia sucroalcooleira da região da mata norte de Pernambuco? Desse modo, o objetivo desta pesquisa é compreender como se 
configura o fornecimento de cana de açúcar na região da Mata Norte de Pernambuco. Para tanto, postulou-se como objetivos específicos: a) entender a percepção dos fornecedores sobre a atuação do governo e das associações sindicais; e b) compreender a percepção dos fornecedores acerca da atuação de cooperativas na gestão das usinas.

A região da Mata Norte é historicamente conhecida pelo plantio de cana, tendo, ao longo da sua história, grandes usinas, como a Petribú, localizada em Lagoa de Itaenga. Esta usina teve sua origem no ano de 1729 sendo conhecida como Engenho Petribú, somente no ano de 1909 o engenho passou a ser usina e no ano de 1911 a família passou a adotar o mesmo nome da usina. Atualmente o grupo Petribú é administrado por Daniela Petribú, primeira mulher a comandar a usina, que produz 20.000 sacos de açúcar diariamente. Já a Cruangi, localizada em Timbaúba, foi fundada no ano de 1918 como Engenho Genipapo. No ano de 1921 o engenho Genipapo mudou de donos e foi substituído pela Usina Cruangi. Esta usina alcançava números significativos de moagem, mas, veio à falência em 2011. Foram quatro anos sem funcionamento, até que foi revitalizada por uma cooperativa no ano de 2015. A Olho D'Agua teve seu início no ano de 1920 quando o Artur Tavares de Melo adquiriu o Engenho Banguê Olho D'Água situado em Camutanga. Atualmente, a usina tem uma moagem de 1.700 .000 toneladas de cana tendo em sua moagem $70 \%$ de cana própria e $30 \%$ de cana de fornecedores. A região, conta ainda com outras usinas e muita produção de cana de açúcar.

Devido à expressividade desta cultura na região e entendendo que o elo de fornecimento tende a sofrer mais pressão nesta cadeia é importante entender como se configura dos fornecedores de cana, pois está é a principal fonte de renda para a região. Os estudos sobre a necessidade de melhoramento contínuo no elo de fornecimento na cadeia de suprimentos das usinas açucareiras se fazem necessários para que sua importância salientada e notada na realidade prática. Desse modo, tornar possível o desenvolvimento dos fornecedores será um grande passo para o setor esta pesquisa pode trazer alguns pontos para a discussão. 


\section{CADEIA DE SUPRIMENTOS E LOGÍSTICA}

De acordo com Ballou (2006, p. 28) "a cadeia de suprimentos abrange todas as atividades relacionadas com o fluxo e transformação de mercadorias desde o estágio da matéria-prima (extração) até o usuário final". Chopra (2011, p.3) acrescenta que a cadeia de suprimentos "consiste em todas as partes envolvidas, direta ou indiretamente, na realização do pedido de um cliente". Sendo assim, esta compreende, não somente os fabricantes, mas também os fornecedores, transportadores e todos os outros envolvidos até chegar aos clientes. Na cadeia de suprimentos se faz necessário que as operações sejam integradas, integração esta que vai desde a compra da matéria prima até a entrega destes bens e/ou serviços ao cliente (BOWERSOX, et al., 2014). Chopra (2013) destaca que o sucesso de uma cadeia de suprimentos está diretamente ligado a capacidade de promover a integração entre seus elos.

As informações que fluem na cadeia são decisivas, pois, servem de base para a tomada de decisão, a qual busca otimizar o desempenho dela. Pires (2013) acrescenta que se faz necessário gerenciar a cadeia tendo uma visão do todo, indo além dos limites da empresa. Isto se dá, visto que as organizações são elos da cadeia e estão interligadas, assim, o sucesso ou fracasso de uma pode influenciar a outra. $O$ objetivo da cadeia de suprimentos é "maximizar o valor geral gerado", assim sendo, "o sucesso dessa cadeia deve ser medido em termos de lucratividade", ou seja, será a diferença entre o que o cliente está disposto a pagar e os custos incorridos no atendimento da demanda (CHOPRA, 2013, p.5).

Desde o surgimento da cadeia de suprimentos ela vem sendo confundida com a logística. Pires (2013, p.40) argumenta que a cadeia de suprimentos "abrange um escopo maior de processos e funções que a logística". Desta forma, esta faz parte dos processos que se encontram envoltos naquela. Wanke (2009) afirma que a logística é o emprego dos recursos utilizados no fluxo dos produtos entre o fornecedor e cliente. Por esta perspectiva este processo compõe a cadeia de suprimentos, mas não em sua totalidade.

$\mathrm{Na}$ logística existem quatro componentes, suprimentos, distribuição, fluxo reverso e processamento interno. A logística de suprimentos como menciona Vasconcelos (2015, p. 18) "é aquela que interliga a empresa e os seus fornecedores", 
nesta etapa da cadeia também se analisa a movimentação dos suprimentos a partir dos fornecedores até a empresa focal. A logística de distribuição é confundida, até hoje, com a própria logística. Para Vieira (2009, p. 51) a logística de distribuição "trata da estocagem, movimentação e transporte de produtos acabados ou semiacabados", tendo como destino final o cliente. A logística reversa surgiu devido à preocupação com o meio ambiente, e hoje representa uma vantagem competitiva se utilizada frente aos concorrentes. Fernandes (2012) define a logística reversa como uma forma de gerenciar o retorno de materiais e bens ao início da cadeia após sua venda ou consumo. A logística interna envolve a movimentação de matéria prima ou componentes para fabricação ou processamento de um produto, gerando informações para a cadeia produtiva (ROCHA et al., 2011).

Neste trabalho será enfatizada a logística de suprimentos, neste elo encontraram-se os fornecedores. De acordo com Fernandes (2012, p. 103) "as finalidades dos suprimentos são: suprir as unidades de produção na quantidade exata, na qualidade requerida, no tempo e local certos dos materiais necessários a industrialização e comercialização". Sendo assim, o componente relativo aos suprimentos tem como objetivo disponibilizar a matéria prima para o setor produtivo, para isso, além do setor de compras, o transporte e o recebimento da matéria prima precisam "trabalhar" de forma eficiente, junto aos fornecedores, pois este elo é de suma importância para o bom funcionamento da cadeia.

Buller (2012) destaca que as cadeias de suprimentos atualmente tendem a consolidar os seus fornecedores, construindo assim parcerias. Pires (2013, p.73) esclarece que "o objetivo é construir relações ganha-ganha e envolver os fornecedores desde a fase inicial de concepção de produtos." Esta é uma parceria que deve ser acompanhada de forma contínua pelos membros da cadeia de suprimentos.

\section{SETOR SUCROALCOOLEIRO}

O plantio da cana de açúcar no Brasil surgiu na Capitania de São Vicente, que hoje abrange os estados do Rio de Janeiro, São Paulo e Paraná, no ano de 1532. Vinda da Ilha da Madeira, trazida por Martin Afonso de Souza, foi nas Capitanias de Pernambuco e da Bahia, que ela encontrou condições ideais para florescer, sendo as terras úmidas do massapê ideais para o seu desenvolvimento (MACHADO, 2017). No 
contexto de Pernambuco o surgimento da cana de açúcar aconteceu, ainda, na primeira metade do século XVI.

Gaspar (2009, p.1) relata que "no início, os engenhos de açúcar devem ter sido movidos à tração humana, como as casas de farinha", o que depois evoluiu para o uso da força dos animais e dos engenhos d'água. Apenas no século XIX houve uma evolução, fruto da revolução industrial que propiciou o surgimento de novos equipamentos, como locomotivas e caldeiras a vapor, os quais melhoraram os processos de transformação e transporte da cana de açúcar.

De acordo com Machado (2017, p.6) "as usinas nordestinas eram responsáveis por toda a exportação brasileira e ainda complementavam a demanda dos estados do Sul". Com essa demanda e tendo matéria-prima em abundância, o que se requeria era a infraestrutura, a qual era adquirida por meio da aquisição de usinas modernas importadas nos mesmo moldes de importação da infraestrutura ferroviária. Conforme Eisenberg (1977, p. 37) "as zonas de açúcar no Nordeste tiveram êxito, com a ajuda governamental, na implantação de tecnologia modernizadora nos engenhos e na ampliação da escala de produção". Isso denota a o setor sempre dependeu de financiamento público.

No intuito de conferir a Pernambuco capacidade para competir com a produção cubana e das ilhas no Caribe, o Governo passou a financiar a instalação de engenhos centrais e as primeiras usinas em moldes que se assemelham que estamos acostumados a ver atualmente. Segundo Gaspar (2009, p.1) "a primeira usina no estado de Pernambuco foi a São Francisco da Várzea, tendo sua primeira moagem no ano de 1875". Contudo, foram os engenhos a vapor que permitiram o início da produção do açúcar cristal no Estado (YONY, 1999).

Pernambuco chegou a ter mais de cem usinas açucareiras (GASPAR, 2009). Na década de 1970, todavia, começou uma nova onda de modernização das usinas, trazendo o uso de equipamentos como o desfibrador e de sistemas de seleção das variedades de cana mais produtivas e resistentes, tudo focado em melhoria de produtividade. No entanto, o setor sucroalcooleiro em Pernambuco não evoluiu muito em sua forma de atuação até anos recentes. Não foram feitos avanços suficientes, em termos de produtividade, para impedir a crise vivenciada pelo setor nos anos 2000, o que levou a uma redução significativa das usinas em atuação, chegando, segundo 
a Nova cana, a existir apenas dezessete usinas de açúcar e álcool em atuação em 2017.

Tendo como foco a retomada do crescimento, o setor sucroalcooleiro em Pernambuco passou a enfrentar uma grande mudança, nos últimos três anos, a revitalização de usinas por meio de cooperativas. Conforme Barbosa (2015) a entrada de cooperativas em usinas que se encontravam fechadas, tais como: Cruangi, Pumaty e Pedrosa, permitiu uma boa colocação do estado no Cadeg (Cadastro Geral de Empregados e Desempregados). Pois, estas usinas já geraram 6 milhões de litros de etanol e 3 toneladas de açúcar, além disso, em plena crise enfrentada no país a revitalização destas usinas gerou12 mil empregos, entre diretos e indiretos.

\section{ASPECTOS METODOLÓGICOS}

O presente estudo se enquadra na abordagem qualitativa, pois se objetivou entender uma realidade social vivenciada em seu ambiente natural. Segundo Creswell (2011, p. 26) a pesquisa de natureza qualitativa "é um meio para explorar e para entender o significado que os indivíduos ou os grupos atribuem a um problema social ou humano". Esta abordagem permite que o pesquisador se insira no ambiente de vivência dos atores em investigação e assim conduza a busca por informações que expressem a realidade em estudo.

Este processo de inserção na realidade do outro viabiliza a realização de uma interpretação da situação em seu contexto originário. Godoy (1995) afirma que como fonte de dados, na pesquisa qualitativa, o pesquisador tem a sua disposição o ambiente natural. Sendo assim, o próprio pesquisador passa a ser parte fundamental no processo de pesquisa, pois ele interfere no ambiente e suas interpretações fazem parte do processo de pesquisa. Neste contexto podem emergir muitas questões cabendo ao pesquisador discerni as informações de relevância para a pesquisa e ter consciência da sua interferência no ambiente.

Como estratégia de investigação optou-se pela pesquisa qualitativa básica. Este tipo de investigação busca entender o modo como os indivíduos interpretam e constroem os significados sobre suas vidas ou compreender estas significações, sendo indicada em estudos que busquem desenvolver tais interpretações a partir das informações compartilhadas pelos atores em seu ambiente natural (MERRIAM, 2009). 
O processo da pesquisa foi se desenhando à medida que se conhecia mais sobre a realidade em estudo. Assim, a coleta de dados se deu por meio de observações não participante e de entrevistas semiestruturadas realizadas a cada inserção no campo em estudo.

De acordo com Lakatos (1991) na observação não participante o pesquisador tem contato com o grupo estudado sem se integrar a ele como participante, todavia, a observação é realizada de modo que permita a obtenção de um fim determinado. As observações aconteceram no engenho Panorama. O momento de realização da pesquisa coincidiu com o período de plantio da cana e permitiu que os fornecedores fossem observados dentro de suas plantações. Estas observações geraram notas de campo que foram digitadas em documento do word, ocasião em que puderam ser acrescentadas informações detalhadas, para posterior análise.

Para Triviños (1987, p. 152) as entrevistas semiestruturadas "mantém a presença consciente e atuante do pesquisador e, ao mesmo tempo, permite a relevância na situação do ator", favorecendo a descrição, explicação e compreensão dos fenômenos sociais. Laville e Dionne (1999) acrescentam que a entrevista semiestruturada é guiada por um roteiro com perguntas abertas já estabelecidas, mas, o pesquisador pode acrescentar perguntas, como também mudar a ordem das mesmas tornando assim a entrevista flexível tanto para as perguntas como para as respostas.

O roteiro de entrevista foi constituído por questões abertas, as quais possibilitaram uma discussão sobre o mercado atual de comercialização da cana de açúcar, bem como, sobre as dificuldades encontradas pelos fornecedores deste produto na região da Mata Norte. Foram entrevistados 11 fornecedores das Usinas Olho D’Agua, Cruangi e Laranjeira. As entrevistas variaram em termos de duração, indo de 3 minutos até 15 minutos. O perfil dos entrevistados pode ser visualizado na figura 1. Após a realização das entrevistas os dados de áudio foram transcritos em texto para dar base à análise. 
Figura 1 - Perfil dos fornecedores entrevistados

\begin{tabular}{|l|l|l|l|l|l|}
\hline Fornecedores & Idade & Formação & $\begin{array}{c}\text { Tempo de } \\
\text { atuação }\end{array}$ & $\begin{array}{c}\text { Usina para } \\
\text { quem fornece }\end{array}$ & Subordinados \\
\hline Fornecedor 1 & 61 & $\begin{array}{l}\text { Fundamental } \\
\text { incompleto }\end{array}$ & 15 anos & Olho D'Agua & 1 \\
\hline Fornecedor 2 & 45 & $\begin{array}{l}\text { Fundamental } \\
\text { incompleto }\end{array}$ & 8 anos & Cruangi & 4 \\
\hline Fornecedor 3 & 60 & $\begin{array}{l}\text { Fundamental } \\
\text { incompleto }\end{array}$ & 10 anos & Cruangi & 0 \\
\hline Fornecedor 4 & 51 & Agrônomo & 12 anos & Olho D'Agua & 9 \\
\hline Fornecedor 5 & 61 & $\begin{array}{l}\text { Fundamental } \\
\text { incompleto }\end{array}$ & 15 anos & Cruangi & 0 \\
\hline Fornecedor 6 & 77 & $\begin{array}{l}\text { Não } \\
\text { informada }\end{array}$ & 40 anos & Cruangi & 3 \\
\hline Fornecedor 7 & 88 & $\begin{array}{l}\text { Não } \\
\text { informada }\end{array}$ & 60 anos & Olho D'Agua & $\begin{array}{l}\text { Não soube } \\
\text { informar }\end{array}$ \\
\hline Fornecedor 8 & 31 & $\begin{array}{l}\text { Médio } \\
\text { completo }\end{array}$ & 30 anos & Olho D'Agua & 2 \\
\hline Fornecedor 9 & 73 & $\begin{array}{l}\text { Fundamental } \\
\text { incompleto }\end{array}$ & 23 anos & Cruangi & 1 \\
\hline Fornecedor 10 & 66 & $\begin{array}{l}\text { Fundamental } \\
\text { incompleto }\end{array}$ & 20 anos & Cruangi & 3 \\
\hline Fornecedor 11 & 61 & $\begin{array}{l}\text { Médio } \\
\text { completo }\end{array}$ & 40 anos & Laranjeira & 24 \\
\hline
\end{tabular}

Fonte: Autoria (2017).

A escolha do objeto de estudo, fornecedores de cana de açúcar da região da Mata Norte, se deu pelo fato de a primeira autora conhecer a região que envolve a Usina Cruangi. Após a falência desta usina e, posterior, entrada da Cooperativa do Agronegócio dos Fornecedores de Cana de açúcar (COAF) houve o despertar de interesse sobre a importância da cultura da cana para a região e cidades vizinhas. Em conversa com seu pai sobre esta realidade houve o conhecimento de que próximo a Cruangi existia um engenho de nome Panorama, o qual contava com uma grande quantidade de fornecedores de cana.

Existe, nesta localidade, uma grande quantidade de fornecedores devido à falência de um grande senhor de engenho que não podendo pagar o tempo de trabalho de seus funcionários dividiu suas terras entre eles que receberam cotas proporcionais à quantidade de anos em serviço. Portanto, são pequenos produtores que vivem da agricultura e fornecem cana para usinas da região, como a própria Cruangi e a Olho D’água. 
Foi neste engenho que em conversa Senhora Zita tomou-se conhecimento de que boa parte da população local trabalhava com o plantio, de cana-de-açúcar e/ou lavoura branca (raízes, como batata doce, macaxeira e inhame) para a comercialização e consumo. Esta senhora atuou como facilitadora e auxiliou marcando datas para realização das entrevistas e mediando o primeiro contato entre pesquisadora e atores estudados.

O processo de realização de entrevistas realizado com dez fornecedores também foi mediado pela senhora Zita que se dispôs a ir junto com a pesquisadora procurar por fornecedores que se encontravam no engenho Panorama. A presença da dona Zita facilitou a abordagem visto que não é algo corriqueiro para eles a recepção de pessoas de fora daquela comunidade. Buscando tornar a conversa mais leve eles foram abordados em seu contexto de atuação, alguns deles se encontravam em suas casas e outros em suas plantações.

Um único fornecedor estudado, o Senhor Severino, não faz parte do engenho Panorama. Este foi contatado por meio de uma colega que o conhece e passou os contatos dele. Ele é um grande fornecedor da Usina Laranjeira, tendo sua plantação situada no engenho Borracha-PE. Por telefone, foi combinado o dia para a entrevista com o mesmo em sua localidade, entretanto, por motivos de saúde a entrevista com o senhor Severino aconteceu por meio de redes sociais, visto que o mesmo se encontrava em outro estado se recuperando de uma intervenção cirúrgica, mas fez questão de contribuir com a pesquisa. Foi importante fazer essa entrevista para ter o contraponto entre pequenos e grandes fornecedores.

\section{RESULTADOS E DISCUSSÃO}

Este artigo objetivou compreender como se configura o fornecimento de cana de açúcar na região da Mata Norte de Pernambuco. A partir da análise das observações e das entrevistas realizadas durante o processo de pesquisa foi possível resumir a configuração do setor de fornecimento de cana de açúcar em quatro tópicos, quais sejam: condições do setor sucroalcooleiro na Mata Norte; a percepção dos fornecedores sobre o governo e associações sindicais; percepção dos fornecedores acerca do desempenho da Cooperativa; e diferentes visões entre pequeno e grande produtor. 


\section{$\checkmark$ Condições do setor sucroalcooleiro na Mata Norte}

Atuar no setor sucroalcooleiro em Pernambuco mostra-se uma tarefa dificultosa, principalmente para o pequeno produtor que por muitas vezes, enfrenta grandes problemas em sua produção. Tais como, o alto custo de manter a produção, o transporte dispendioso ou em más condições e as queimas que segundo os fornecedores são uma das maiores dificuldades encontradas ao atuar neste setor.

Sem os incentivos governamentais o pequeno produtor encontra dificuldades. Como citado pelo Fornecedor 1 a "Dificuldade é o dinheiro que não tem, o cara moi a cana quando recebe o dinheiro já ta devendo". Diante deste cenário os produtores precisam procurar outros recursos, como os empréstimos, para conseguir manter a produção. Foi o que aconteceu com o fornecedor 4: "Eu peço dinheiro no banco, um exemplo de quinze mil reais pra pagar com cinco anos, e dois anos de carência". Este ciclo acaba gerando para o pequeno produtor dívidas de longo prazo, dinheiro este que poderia estar sendo investido em adubação ou transporte, por exemplo.

Sem planejamento e correndo o risco de não obter o retorno esperado da produção estes produtores acabam, muitas vezes, tendo que recorrer a novos empréstimos para garantir a continuidade de suas atuações. Conforme Azevedo (2017, p. v) "identificar novas alternativas para as unidades de produção familiar, que almejem melhorar o ambiente de produção, gerando renda capaz de permitir, além da sobrevivência, a realização social e econômica, caracteriza-se como um desafio para o pequeno produtor". Neste caso este estudo expressa que este desafio está longe de ser superado na região em foco.

Outro ponto que gera insatisfação no produtor é o transporte. Para Vieira (2009, p. 205) "a importância de uma eficiente administração dos transportes reside no fato de ele ser um dos componentes de custo mais relevantes numa cadeia de suprimento". O fornecedor 2 declarou que além de acontecer, muitas vezes, de não ter transporte quando tem o mesmo pode quebrar e "se quebra no caminho, passa dois, três, quatro dias e nossa cana fica na palha aqui secando", essa ruptura acaba gerando um prejuízo para o fornecedor que perde a qualidade da cana de açúcar. No momento do transporte acontece também de a cana cair no percurso devido ao mau acondicionamento no caminhão o que gera perdas para o produtor. Sobre este assunto o fornecedor 11 afirma "o sistema de transporte, que em minha opinião é péssimo, o transporte da cana de açúcar tem vários problemas, atrasa muitas vezes, 
muitas canas caem no caminho e isso é prejuízo para nós produtores". Desse modo visualiza-se que esta incerteza na existência do transporte no momento adequado acaba por comprometer a qualidade do produto ofertado diminuindo o valor agregado e a falta de adequação no acondicionamento para transporte acarreta a perdas de produto no caminho, o que além de ser prejudicial aos produtos pode acabar gerando acidentes nas estradas.

Pode-se observar que pela falta de transporte alguns fornecedores do engenho Panorama acabam deixando de fornecer para a usina Cruangi, mesmo que ela seja a usina de localização mais próxima da produção deles. Alguns dos entrevistados citaram que antigamente a usina Cruangi disponibilizava transporte para os fornecedores levarem suas canas, situação diferente com a cooperativa, pois, a mesma não disponibiliza o transporte, por este motivo muito dos fornecedores preferiram escoar sua produção para a usina Olho D’água, optando, assim, por um comprador mais distante devido às impossibilidades de lidarem sozinhos com a questão do transporte. Talvez a associação entre eles para usarem um transporte compartilhado pudesse melhor o poder de negociação. Mas, como apontado por Farias Filho e Pires (2013) a forte influência familiar em grupos de trabalho tendem a fechar o grupo que acaba por evitar a criação de alianças entre atores fora de seu círculo familiar, ou seja, o foco na sobrevivência familiar acaba por minar as relações intergrupos.

Outro problema enfrentado pelos produtores são os incêndios, que, na maioria dos casos, acontecem de forma criminosa. Quando a cana é queimada antes do tempo previsto gera um custo muito alto para o fornecedor, pois ela perde valor e o produtor tem que vender a cana mais barata. Podendo até haver a perca total na plantação dependendo da proporção do incêndio, e neste caso o agricultor vê todo o trabalho e investimento ser desperdiçado. Foi o que aconteceu em 2016 na região do engenho Panorama como explana o fornecedor 8: "no ano passado foi muita luta para a gente, colocaram fogo em tudinho, queimaram tudo de uma vez antes de chegar o tempo". Assim, existem, ainda, os custos de perdas por fatores externos a atividade produtiva, nesse cenário, como manter um planejamento de produção e se desvencilhar da dependência de financiamento, em caso aconteça um incêndio de larga proporção, o qual não seria previsto? 


\section{$\checkmark$ Percepção dos fornecedores sobre o governo e associações sindicais.}

O desempenho do governo em relação ao setor foi de opinião unanime entre os fornecedores, todos reclamaram sobre a atuação deste no contexto atual. Eles comentaram que antes eram oferecidos subsídios, em forma de adubo. $O$ fornecedor 1 foi o último a receber, a três anos atrás. Quando eles recebiam esta ajuda do governo seus custos eram diminuídos, o que para as condições de trabalho deles eram de extrema importância. É importante salientar que os sistemas de gerenciamento público mudaram nas duas últimas décadas com a migração para um sistema gerencial. Nesse sentido linhas de crédito e sistemas de incentivo a agricultura foram formalizados de modo a gerar mais transparência e permitir a criação de indicadores de eficiência (CONSELHO EMPRESARIAL BRASILEIRO PARA O DESENVOLVIMENTO SUSTENTÁVEL, 2014). Esse processo foi importante para evitar a troca de favores nas eleições, no entanto, muito pequenos agricultores de regiões mais vulneráveis não se familiarizaram totalmente com os novos sistemas e muitas vezes acabam por não usufruir deles.

Um dos fornecedores pontuou que depois da crise econômica, que o país enfrentou, os auxílios advindos do governo foram diminuindo até acabarem totalmente. O fornecedor 10 informou "teve ai o tempo de Dilma ela fez uma grande reunião lá em Recife pra a gente tudinho participar, ela falou no subsídio, ai deu $12 \%$ até hoje ninguém nem vê falar, ninguém nunca recebeu". Ele sente-se perdido, pois, nenhuma informação é repassada para eles sobre a situação e o que foi acertado nunca se realizou, havendo apenas a expectativa frustrada.

Todos os 10 pequenos fornecedores informaram que não participam de nenhum tipo de associação ou sindicato. Foi observado, inclusive, que alguns deles têm um sentimento de que as associações não beneficiariam em nada, falam com um pouco de desanimo, um deles destacou "tem um sindicato mais é perdido" (FORNECEDOR 1), outro afirmou que "não tinha futuro nenhum" (FORNECEDOR 2) se associar, pois o mesmo sente que não é ajudado por essas entidades. O fornecedor 9 citou que com o sindicato ou as associações "aumentava mais dinheiro para a gente", ou seja, eles poderiam receber dinheiro ou ajuda destes órgãos para o plantio da cana, mas acaba havendo certa descrença nestas instituições.

Também foi observado que os agricultores nutrem um sentimento de abandono por parte do governo e que sentem que as associações sindicais não são entidades 
que representem e lutem por eles. Neste cenário eles ainda estão se adaptando a atuar no mercado sem a ajuda do governo e acabam não conseguindo ter êxito. Colocar toda responsabilidade na mão dos pequenos fornecedores é algo que pode enfraquecer o mercado, visto que, sem a ajuda e com custos elevados fica difícil sobreviver neste setor. Salienta-se que se eles não conseguirem resistir acarretará em um grande problema para a região porque se eles ficam endividados e não conseguem sobreviver dentro deste mercado eles terão dificuldades de encontra outra ocupação que gere renda, pois, esses fornecedores são antigos empregados de engenho e após ganharem as terras continuaram plantando a cana e sendo fornecedores, pois esta era a única coisa que eles poderiam fazer visto que é a opção que a região oferece para os fornecedores, contudo eles são um elo fundamental na cadeia.

Os fornecedores também sentem falta de uma relação mais próxima com as usinas. O fornecedor 2 acredita que, se todos os fornecedores fossem até as usinas a fim de pedir melhorias, seria bom para todas as partes. Já o fornecedor 11 argumentou que a relação entre comprador (usina) e vendedor (fornecedor) deveria ser melhorada, ele declarou que as usinas "muitas vezes atrasam pagamentos ou querem comprar a tonelada a um valor abaixo do mercado, tudo isso dificultando o nosso trabalho [trabalho dos fornecedores]" vale ressaltar que este é um grande fornecedor, e mesmo assim ele enfrenta o problema da usina exercer grande poder sobre ele, se formos comparar com os pequenos fornecedores esta situação seria ainda pior.

Melhorar as condições de venda também é fundamental, não adiantaria haver incentivos governamentais e melhores condições de transporte, se ao vender a cana o fornecedor for prejudicado pelo poder exercido pela usina. Conforme Porter (1986) os fornecedores podem pressionar a indústria, ameaçando aumentar os preços ou reduzir a qualidade e/ou os serviços envoltos nos produtos vendidos. Para tanto, algumas questões propiciam este poder aos fornecedores, quais sejam: o grupo de fornecedores é dominado por poucas companhias e é mais concentrado do que a indústria compradora; os fornecedores não precisam lidar com substitutos; a indústria não é um cliente importante para o fornecedor; o produto negociado é importante para o comprador; os produtos ofertados são diferenciados ou o comprador incorre em custos para mudar de fornecedor; existe a ameaça concreta de integração para frente 
do fornecedor. Neste caso entende-se que o poder está com a indústria e uma forma de melhorar essa relação seria a atuação dos fornecedores em conjunto para negociarem em bloco o que não se configura no caso em estudo.

\section{$\checkmark$ Percepção dos fornecedores acerca do desempenho da cooperativa}

Em relação à cooperativa, os entrevistados, em sua maioria, mostraram-se bastante agradecidos, pois, quando a usina Cruangi parou de funcionar boa parte dos pequenos produtores da região ficaram sem ter para quem vender a cana de açúcar. Mesmo com a cooperativa trabalhando de forma diferente dos antigos donos da Usina Cruangi, atualmente após alguns anos de gestão da cooperativa na usina, os fornecedores começam a perceber as diferenças entre as duas gestões. Mas, eles têm preocupações mais imediatas, como ter para quem vender seu produto, esses detalhes acabam ficando em segundo plano, quando há alguma percepção sobre eles.

Os fornecedores têm perspectivas diferentes sobre as usinas. Foi comum ouvir que hoje a cooperativa não disponibiliza transporte como era feito anteriormente. Alguns citaram o nome de um antigo gestor da usina e falaram que na gestão dele era disponibilizado transporte para a cana de açúcar e a moagem era bem maior, assim os fornecedores conseguiam vender uma maior quantidade de cana. O fornecedor 2 quando questionado sobre o desempenho da cooperativa informou que antes era melhor "porque tinha carro, a gente cortava [refere-se a cana] no dia e pedia carro, no outro dia tinha carro, carregadeira, abel [equipamento que coleta a cana, que já está cortada, do chão e coloca dentro do caminhão], tudo". Hoje ele relata que precisam pagar pelos serviços terceirizados para transportar a cana até a usina, ele também citou que esses transportes são difíceis de encontrar e até mesmo quando se encontra os veículos estão em condições ruins de funcionamento. O fornecedor 5 relatou que com a gestão antiga era melhor "porque o carro do transporte era dele [refere-se ao antigo gestor], carregadeira, tudo, ai pronto era tudo por conta da Usina. A gente só fazia moer e receber". Este transporte era uma grande ajuda para os pequenos fornecedores.

Porém, alguns informaram que preferiram não ter o transporte, pois, sendo assim, com o corte e transporte por conta deles sairia mais barato, já que a usina paga o frete como declarou o fornecedor 8 . O fornecedor 3 acrescenta que "dá o frete a 
gente", tendo a produção dele um maior lucro. Vale ressaltar que vendo o cenário atual pode haver mais perda do que ganho, pois a cana pode perder seu valor por ficar muito tempo esperando o transporte como citado pelos entrevistados. Em contrapartida, a cooperativa foi boa para o pequeno produtor, pois, os mesmos se encontravam parados ou vendendo em negociação acirrada com outras usinas da região. O fornecedor 10 destacou que com a cooperativa quem estava sem vender voltou ao mercado e como o pequeno produtor sobrevive com o que vende, foi de grande ajuda, e esta ajuda não foi só pra o fornecedor mais para todas as pessoas que dependiam da usina economicamente. O fornecedor 11 observa que com as cooperativas os pequenos produtores podem investir em suas produções já que o "valor da venda da tonelada subiu um pouco" e também o pequeno produtor pode procurar benefícios junto com a cooperativa.

\section{$\checkmark$ Diferentes visões entre pequeno e grande produtor}

Com as entrevistas e observações pode-se analisar que os pequenos e grandes produtores possuem visões diferentes sobre o setor. O fornecedor 11, que é um grande produtor, está bastante preocupado com a qualidade da cana e de como ela vem caindo ao longo dos anos, ele afirma que identifica que a qualidade da cana está visivelmente "mais fraca devido aos problemas de solo e pulverização desregulada" e que "tudo isso afeta o mercado". Já o pequeno produtor está mais preocupado com a falta de incentivo e as dificuldades encontradas no transporte sendo uma questão quase unanime entre os pequenos fornecedores aqui entrevistados. O pequeno produtor está focado em questões mais imediatas e que impactam na sua sobrevivência e por isso a questão de melhorias nos processos acaba ficando a margem.

No concernente as cooperativas o grande fornecedor também expõe uma visão divergente aquela expressa pelos pequenos. Ele acredita que as cooperativas podem enfraquecer o mercado, visto que "a cooperativa age de uma forma e os produtores são acostumados a agir de outra". A meu ver o pequeno produtor não consegue ter uma visão crítica sobre as cooperativas, eles não se posicionam acerca do assunto de modo contundente, aparentam não saber muito sobre como as cooperativas influenciam no setor. $E$ isso faz sentido devido ao baixo envolvimento dos pequenos 
produtores nas decisões dentro da cadeia produtiva, visto que se detona uma centralidade nas usinas e em grandes produtores.

Outra visão diferente a ser discutida é sobre o subsídio oferecido pelo governo. O grande fornecedor, aqui estudado, tem uma forma diferente de agir em relação à falta do subsídio, isto acontece porque ele nunca recebeu e mesmo com as condições difíceis do mercado conseguiu se manter em atividade sem a ajuda do governo, já o pequeno fornecedor tem uma dependência maior do governo, hoje sem essa ajuda eles encontram uma maior dificuldade em se manter no setor. No entanto, se faz necessário buscar soluções para propiciar a sustentabilidade da cadeia sem tamanha

dependência do governo. É importante, contudo, entender que os atores tem poderes diferentes e, portanto, precisam ser analisados de formas diferentes, assim, as formas de estímulo e promoção da sustentabilidade dos pequenos produtores são fundamentais e dependem de auxílio governamental, sem que esse processo seja continuado por tempo indeterminado.

\section{CONSIDERAÇÕES FINAIS}

No que concerne a proposta desta investigação quanto a elucidação da configuração do elo de fornecimento da cadeia de suprimentos sucroalcooleira têmse como resultantes os tópicos e subtópicos relacionados na figura 2.

Como visto nos resultados, o elo de fornecimento da cadeia sucroalcooleira na região abordada não está posicionado como um elo forte. Ter o subsídio existente tirado deles de forma inesperada só mostra o quanto o segmento é dependente e de certa forma inexpressivo, em termos de poder. Sem os subsídios e sendo "esmagados" pelo grande poder das usinas os pequenos fornecedores tem uma estrutura de produção precária. Neste contexto, os mesmos e veem em uma situação difícil, na qual os custos de manter suas plantações são grandes e os lucros pequenos. Muitos recorrem a empréstimos bancários para conseguir plantar ou trabalham sozinhos nas suas plantações por não terem dinheiro para contratar mão de obra. Os fornecedores veem que as pessoas tem uma percepção diferente da realidade vivida por eles, pois as pessoas costumam associar os fornecedores de cana a pessoas com um alto poder aquisitivo, contudo a maioria dos pequenos produtores só tem o dinheiro ganho no período da safra pra sobreviver ao resto do ano, isso quando não tem 
dívidas assumidas de empréstimos anteriores e se der tudo certo na colheita daquele ano.

Figura 2 - Configuração do elo de fornecimento da cadeia suprimentos sucroalcooleira na Mata Norte de Pernambuco

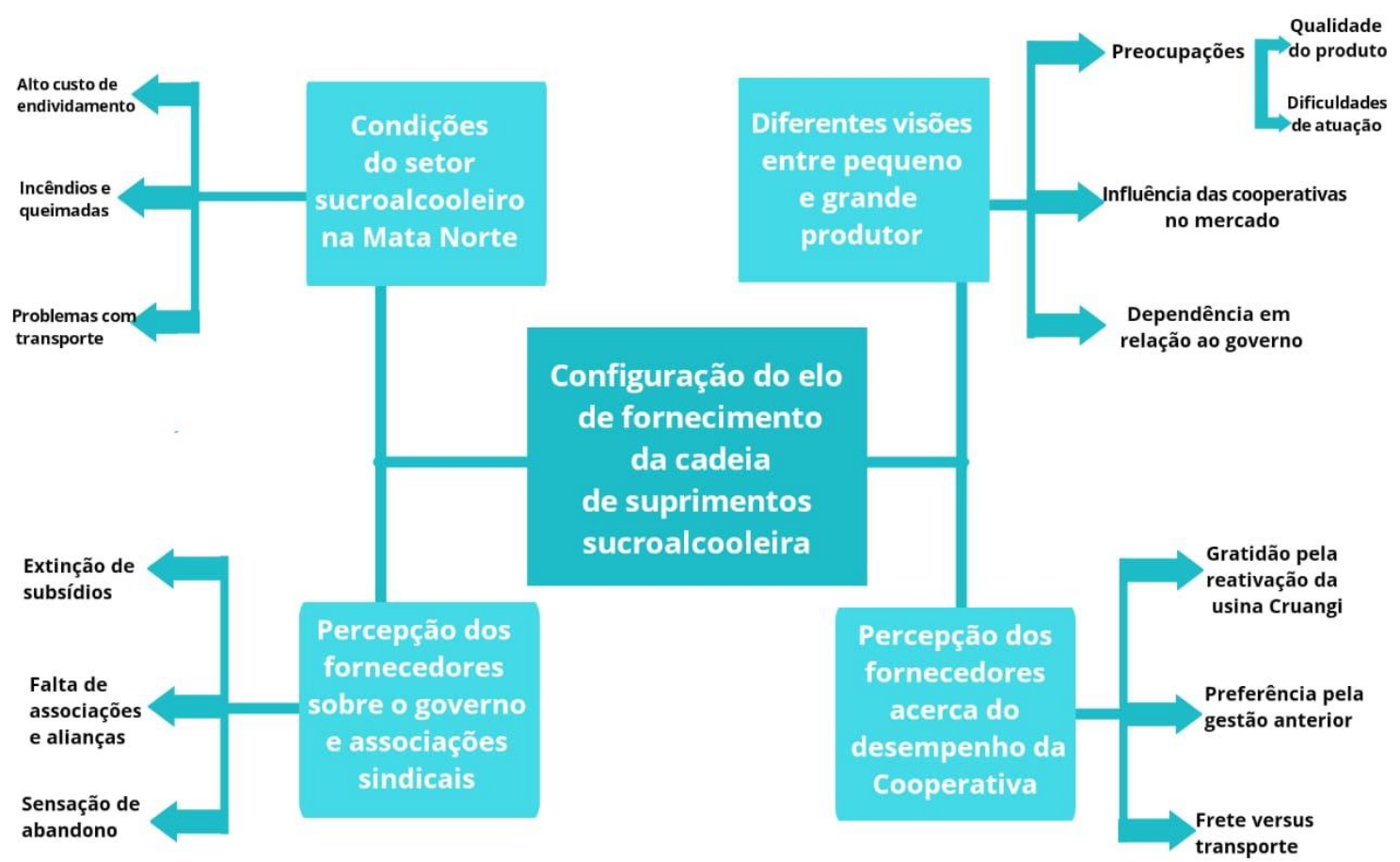

Fonte: Autoria (2020)

As usinas exercem um grande poder sobre os fornecedores (pequenos e grandes), isto acontece devido ao fato de a usina ser a única opção para os fornecedores escoarem sua produção. Este poder exercido pela usina advém desde o surgimento do setor e é exercido não só sobre os fornecedores, mas, também, sobre todas as pessoas da localidade, por ser esta uma das únicas fontes de geração de emprego e, por conseguinte, renda, existente na região. Esta dependência afeta o setor, pois, os fornecedores precisam se moldar conforme a usina. Diante deste cenário os pequenos fornecedores não conseguem se sustentar sozinhos e isso compromete o desenvolvimento socioeconômico de toda a macrorregião. Entretanto, as usinas, apesar de ser o elo forte da cadeia, enfrentam dificuldades em se manterem ativas, haja vista a redução do setor e a necessidade de revitalização por meio da gestão cooperada. Isso demonstra a estagnação e retração de um setor que historicamente foi e, ainda é, a força motriz de uma vasta região. 
Foi possível observar que as pessoas se sentem esquecidas, não tendo outras oportunidades, sendo este setor a única oportunidade de trabalho, seja na indústria ou no campo. A abertura da usina Cruangi, por exemplo, veio como sendo a única "salvação" para os moradores que dependiam da mesma. Com a cooperativa pode existir problemas, mas, sem ela não tem nada, sentimento expresso por todos. Isso aconteceu porque a usina é a única fonte de emprego para muitas das pessoas daquela região. A reabertura desta usina gerou uma comoção tão grande que até missas foram celebradas em agradecimento.

A maioria dos entrevistados não possuía qualificação formal, praticamente não existiam cursos técnicos ou superiores na região na época que eles estavam em formação. Isto retrata uma realidade vivida em um passado recente, na qual o acesso a oportunidades de qualificação era restrito e as pessoas tinham como opção trabalhar como motorista (era o ápice para a maioria dos homens da região) ou no campo, em geral no corte da cana-de-açúcar (onde trabalho exige mais fisicamente). Acredita-se que se os pequenos fornecedores ali instalados tivessem auxílio e incentivos para melhorar tecnicamente suas condições de trabalho isso seria refletido na economia da região, visto que, teria um aumento na renda dos mesmos, o que possivelmente corroboraria para ampliação da geração de emprego.

Entende-se, assim, que se faz necessário entender como manter o setor em funcionamento ou quais as alternativas viáveis a geração de emprego e renda na região. Para tanto se faz necessário entender o funcionamento da gestão cooperada e está a uma sugestão para estudo futuros. Seria interessante ter um diagnóstico da atuação da cooperativa na gestão da usina Cruangi e seus desdobramentos na cadeia de suprimentos sucroalcooleira na Mata Norte.

\section{REFERÊNCIAS}

ANDRADE, M. C. Os rios-do-açúcar do Nordeste Oriental: os rios Coruripe, Jequiá e São Miguel. 2.ed. Maceió: EDUFAL, 2010.

AZEVEDO, C. P. de. Apresentação. In: SILVA, L; de J. de S.; ROCHA, R. N. C. da; MENEGHETTI, G. A.; MORENO, A. A.; FERNANDES, V. Diagnóstico dos sistemas de produção dos agricultores familiares, produtores de mandioca das comunidades do município do Careiro. Embrapa Amazônia Ocidental, Manaus, 2017. Disponível em: https://www.embrapa.br/busca-de-publicacoes/-/publicacao/1084328/diagnostico-dossistemas-de-producao-dos-agricultores-familiares-produtores-de-mandioca-dascomunidades-do-municipio-do-careiro. Acesso em: 24 abr. 2020. 
BARBOSA, M. G1.Pernambuco reativa três usinas e gera 12 mil empregos em plena crise. Disponível em : http://g1.globo.com/pernambuco/noticia/2015/11/pernambuco-reativatres-usinas-e-gera-12-mil-empregos-em-plena-crise.html. Acesso em: 11 jan. 2020.

BALLOU, R. H. Gerenciamento da cadeia de suprimentos/logística empresarial. 5.ed. Porto Alegre: Bookman, 2006.

BOWERSOX, D.J.; CLOSS, D. J.; COOPER, M. B.; BOWERSOX, J. C. Gestão logística da cadeia de suprimento. 4.ed. Porto Alegre: AMGH, 2014.

BULLER, L.S. Logística empresarial. Curitiba, PR: IESDE Brasil, 2012.

CONSELHO EMPRESARIAL BRASILEIRO PARA O DESENVOLVIMENTO SUSTENTÁVEL. Financiamento para pequenos e médios produtores rurais. Rio de Janeiro, 2014. Disponível em: https://cebds.org/publicacoes/financiamento-para-pequenose-medios-produtores-rurais/. Acesso em: 24 abr. 2020.

CREWELL, J.W. Projeto de pesquisa: métodos qualitativos, quantitativos e misto. 3. ed. Porto Alegre: Artmed, 2010.

DIAS, F. Por onde anda o açúcar?. Diário de Pernambuco: 2017. Disponível em: http://www.diariodepernambuco.com.br/app/noticia/economia/2017/10/02/internas economia ,724707/por-onde-anda-o-acucar.shtml. Acesso em: 22 out. 2019.

EISENBERG, P. L. Modernização sem mudança: a indústria açucareira em Pernambuco, 1840-1910. Rio de Janeiro, Paz e Terra; Campinas, Universidade Estadual de Campinas, 1977.

FARIAS FILHO, M. C.; PIRES, J. O. M. A Influência das Redes Sociais de Catadores na Cadeia Produtiva da Reciclagem. Gestão e Sociedade. Belo Horizonte, v. 7, n.17, maioagosto, 2013. https://doi.org/10.21171/ges.v7i17.1857

FERNANDES, K. S. Logística: fundamentos e processos. 1. ed. Curitiba, PR: IESDE Brasil, 2012.

FIESP. Retomada lenta e gradual na colheita de cana. Globo rural: 2017. Disponível em: http://revistagloborural.globo.com/Publicidade/Fiesp-Apresenta/noticia/2017/05/retomadalenta-e-gradual-na-colheita-de-cana.html. Acesso em: 22 out. 2019.

FIGUEIREDO, K. L.; FLEURY, P. F.; WANKE, P. Logística e gerenciamento da cadeia de suprimentos: planejamento do fluxo de produtos e dos recursos. 1. ed. São Paulo: Atlas, 2009.

GASPAR, L. Usinas de açúcar de Pernambuco: pesquisa escolar online. Recife: Fundação Joaquim Nabuco. Disponível em:

http://basilio.fundaj.gov.br/pesquisaescolar/index.php?option=com content\&view=article\&id= 755. Acesso em: 8 jan. 2020.

GODOY, A. S. Introdução à pesquisa qualitativa e suas possibilidades. Revista de Administração de Empresas. São Paulo: v. 35, n.2, p. 57-63, abr. 1995. https://doi.org/10.1590/S0034-75901995000200008

LAKATOS, E. M. Fundamentos de metodologia cientifica. 3. ed. São Paulo: Atlas, 1991. 
LAVILLE, C.; DIONNE, J. A construção do saber: manual de metodologia da pesquisa em ciências humanas. Porto Alegre: Artes Médicas; Belo Horizonte: UFMG, 1999.

MACHADO, F. B. P. Brasil, a doce terra- História do Setor. Disponível em: https://www.agencia.cnptia.embrapa.br/Repositorio/historia da cana 000fhc62u4b02wyiv80 efhb2attuk4ec.pdf. Acesso em: 15 abr. 2017.

MERRIAM, S.B. Qualitative research: a guide to design and implementation. San Francisco: Jossey-Bass, 2009.

NOVACANA. Usinas de açúcar e álcool no estado: Pernambuco. Disponível em https://www.novacana.com/usinas-brasil/nordeste/pernambuco/. Acesso em: 8 jan. 2020.

PORTER, M. E. Estratégia competitiva: técnicas para análise de indústrias e da concorrência. Rio de Janeiro. Campus, 1986. Introdução, caps. 1 e 7, p. 22-48, p. 130-155.

PIRES, S. R. I. Gestão da cadeia de suprimentos: conceitos, estratégias, práticas e casosSupply chain management. 2. ed. São Paulo: Atlas, 2013.

PIRES, S. R. I. Gestão da cadeia de suprimentos: conceitos, estratégias, práticas e casosSupply chain management. 2. ed. São Paulo: Atlas, 2010.

ROCHA, D. A. TABOADA, C. BOUZON, M. CASARIN, N. Planejamento de cenários logísticos. Curitiba, PR: IESDE, 2011.

TRIVIÑOS, A. N. S. Introdução à pesquisa em ciências sociais: a pesquisa qualitativa em educação. São Paulo: Atlas, 1987.

VASCONCELOS, J. Gestão da cadeia de suprimentos. São Paulo: Rede Internacional de Universidades Laureate, 2015.

VIEIRA, H.F. Gestão de estoques e operações industriais. IESDE, 2009. Disponível em: https://pt.scribd.com/document/244626604/GESTAO-DE-ESTOQUES-E-OPERACOESINDUSTRIAIS-pdf. Acesso em: 17 de out. 2017

YONY, S. Açúcar amargo: crise e perspectivas da indústria sucroalcooleira em Pernambuco. Recife: Ed. Universitária da UFPE, 1999.

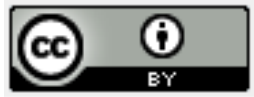

Artigo recebido em: 14/05/2020 e aceito para publicação em: 20/09/2020 DOI: http://dx.doi.org/10.14488/1676-1901.v20i3.4051 